\title{
Children's Cognition and the Inference of Life Phenomenon about Anthropomorphic Characters
}

\author{
Boram No, Soonhyung Yi \\ Department of Child Development and Family Studies, Seoul National University, Seoul, Korea \\ 의인화된 캐릭터에 대한 유아의 생명현상 인지 및 추론 \\ 노보람, 이순형 \\ 서울대학교 아동가족학과
}

\begin{abstract}
Objective: This study aimed to investigate the cognition of life phenomenon regarding anthropomorphic characters according to the characters' properties amongst children aged 3, 4, and 5. Methods: 95 children aged 3 to 5 years from two child-care centers located in Seoul and Gyeonggido participated in this study. Each child was interviewed individually and completed cognition and inference of life phenomenon tasks.

Results: First, preschoolers considered anthropomorphic animal characters as animals. Children aged 3, 4, and 5 were likely to refer to the animation characters as alive and considered animation characters to have many biological and psychological traits. Second, there were significant differences in children's inferences of life phenomena according to the properties of the anthropomorphic characters. Preschoolers considered low anthropomorphic animation characters to have more biological traits and reality. For low actuality characters, preschoolers considered them to have more reality. Third, there were significant differences in children's inferences of reality according to their age: 5-year-olds were more likely to infer the animation character as an imaginary entity, compared to 3-year-olds.

Conclusion: As the literature related to children's cognition about anthropomorphic characters is limited, this study investigated what children think about animation characters and offers useful guidelines for the development of educational media or applications for young children.
\end{abstract}

Keywords: cognition of life phenomenon, inference of life phenomenon, anthropomorphic animal character, animation character$$
\text { 서론 }
$$

유아가 살아가는 일상생활의 맥락에서 의인화된 캐릭터는 친 숙한 존재이다. 유아는 의인화된 캐릭터가 나오는 만화를 자 주 보고, 의인화된 캐릭터가 그려진 옷을 입거나 생활용품을 사용한다. 의인화된 캐릭터는 실제 현실에 존재하지 않지만 애니메이션 속에서는 생동감 있게 살아 움직인다. 의인화된

Corresponding Author: Boram No, Department of Child Development and Family Studies, Seoul National University, 1, Gwanak-ro, Gwanak-gu, Seoul, Korea

E-mail: borino@snu.ac.kr
\end{abstract}

캐릭터는 유아의 생활과 밀접하게 관련이 있는데 반해 유아가 의인화된 캐릭터에게 생명현상을 인지하는지 여부는 알려져 있지 않다. 유아는 의인화된 캐릭터를 살아있다고 여길까? 유 아는 의인화된 캐릭터를 동물로 인지할까 아니면 사람으로 인 지할까? 그리고 의인화된 캐릭터는 유아에게 실재하는 존재 로 여겨질까 가상의 존재로 여겨질까? 본 연구는 이러한 궁금 증에서 시작되었으며, 유아가 의인화된 캐릭터를 살아있는 존

(C)The Korean Association of Child Studies

This is an Open Access article distributed under the terms of the Creative Commons Attribution Non-Commercial License (http:// creativecommons.org/licenses/by-nc/4.0) which permits unrestricted noncommercial use, distribution, and reproduction in any medium, provided the original work is properly cited. 
재로 여기는지 알아보고자 한다.

생물개념 발달에 관한 연구들은 유아가 생물과 무생물 범 주를 구분할 수 있는지에 주목하여 왔는데, 이는 가장 기초적 이며 중요한 능력이기 때문이다(Opfer \& Gelman, 2011). 생물 과 무생물을 구분하는 기준인 생명은 생명현상을 통해 이해될 수 있는데, 생명현상은 생명체가 살아가면서 보이는 발생, 성 장, 번식, 쇠퇴 등의 현상을 말한다(D. Jeon \& Moon, 2012). 생 명현상 인지는 주어진 대상이 이러한 생명현상을 보이는 살아 있는 존재임을 아는 것이다. 기존 연구는 유아가 전형적인 생 물과 전형적인 무생물의 속성을 지닌 대상을 구분하여 생명현 상을 인지하는지를 검토하였다. 하지만 범주 경계선에 있는 대상을 유아가 어떻게 이해하는지 살펴보는 연구는 많지 않 다. 생명현상 인지에서 경계선적 대상(boundary object)은 생물 과 무생물의 속성을 동시에 가지고 있는 대상을 말한다(Okita, Schwartz, Shibata, \& Tokuda, 2005). 경계선적 대상은 유아가 기존에 가지고 있던 범주화 기제에 갈등을 유발함으로써 유아 의 생물개념 발달을 확인할 수 있는 방법이기 때문에 유용하 다(M. K. Kim, 2017; Okita \& Schwartz, 2006). 또한 대상의 어 떤 속성이 대상을 살아있는 것으로 인식되게 만드는지를 확인 함으로써 유아의 생명현상 인지의 특성을 알아낼 수 있을 것 으로 기대된다.

경계선적 대상을 통하여 생명현상 인지를 살펴본 연구들은 대상을 로봇에 한정하고 있다. 로봇은 생명을 모사하고자 하 는 노력에 의해 자발적인 움직임과 정서적 반응이 가능해졌으 며, 생명과 인공물의 경계에 있는 것으로 보인다. 하지만 물리 적으로 존재하지 않지만 정서적으로 살아있다고 여겨지는 경 계선적 대상에 대한 연구는 매우 제한된 실정이다. 산타클로 스나 마녀 같은 가상의 존재를 유아가 생리적 특성과 심리적 특성이 있는 물리적 실재로 여기는지에 관한 연구가 이루어졌 을 뿐이다(Sharon \& Woolley, 2004). 애니메이션은 창조와 재 현의 경계에서 리얼리티를 변형하여 실제 세계보다 더욱 실재 같은 상징을 만들었다(Hong, 2008). 하지만 이러한 애니메이 션 속에서 생동감 있게 살아 움직이는 의인화된 캐릭터가 유 아에게 어떻게 인지되는지에 대한 연구는 이루어지지 못했다.

의인화된 캐릭터는 성인에게도 살아있는 존재로 인식될 수 있다. 다시 말해 성인도 의인화된 캐릭터를 단순히 만화나 그 림으로만 보는 것이 아니라 생명이 있는 인간처럼 지각하는 것이다. $\mathrm{AMRI}$ 를 통하여 의인화된 캐릭터를 보았을 때 뇌의 어 느 영역이 활성화되는지 알아본 연구에서(Sung, Lee, \& Jung, 2004), 생명 유무를 범주화하는 영역으로 알려진 하후두이랑 (inferior occipital gyrus)과 하두정소엽(inferior parietal lobule)이
활성화되었다. 즉, 성인들도 의인화된 캐릭터를 보면서 그 캐 릭터가 살아있는지 아닌지 여부를 판단하고 있다는 것을 알 수 있다.

애니메이션 캐릭터가 의인화 될 수 있는 것은 사실 우리에 게 의인화를 수용할 수 있는 준비가 되어있기 때문이다. 사진 적 재현을 기반으로 하는 애니메이션이 현실감을 획득하기 위 해서는 '믿는 체'라는 관습이 필요하고, '말하는 쥐'가 존재한 다고 '믿는 체'했을 때 비로소 미키마우스는 살아서 움직이는 주인공이 될 수 있다(Kum, 2004). 또한 인간 의식 속에 의인화 를 자연스럽게 수용할 수 있는 의인화 동인이 있는데, 그 중의 하나로 애니미즘을 꼽을 수 있다(S.-W. Park, 2003). 애니미즘 (animism)은 생명이 없는 모든 자연물에 생명과 감정을 부여 하는 경향으로 정의되는데(“animism," n.p.), 이 용어는 종교학 에서 모든 대상에 영혼이 있다는 믿음의 의미로 사용되기 시 작하였고, 심리학에서는 생명이 없는 존재에 생명을 부여하는 의미로 사용된다(Guthrie, 1993). 애니미즘은 초기 인간을 지 배하던 세계관이자 아동의 사고방식으로, 모든 것은 살아있으 며 정신이 있고 생명이 있다는 보편적 생명주의에 기초하고 있다(S.-W. Park, 2003). 아동의 애니미즘은 물활론적 사고라고 도 하며 피아제에 의해 본격적으로 탐구되었다.

Piaget (1929)는 개념 조작 능력이 발달하지 못한 전조작기 유아는 직관적이고 자기중심적 인지구조를 가지고 있기 때문 에 물활론적 사고를 보인다고 판단하였다. 즉, 유아는 자기중 심성이라는 인지적 제약으로 생명이 없는 사물과 자연물에 의 도와 목적이 있다고 여기는 물활론이 나타나는 것이다. Piaget 는 전조작기 유아는 생명현상을 이해하지 못하며, 아동이 구 체적 조작기를 지나야 물활론적 사고가 사라지고 과학적이 고 체계적인 사고를 하게 된다고 주장하였다. 아동의 물활론 적 사고는 전통적으로 아동의 인지적 한계로 이해되었지만, 아동 스스로가 가장 잘 알고 있는 존재인 '나(인간)'에 빗대어 새로운 대상을 이해하려는 전략으로 해석되기도 한다(Turkle, 2005).

유아의 애니미즘적 사고 경향과 의인화된 캐릭터와의 관 령성에도 불구하고 유아가 의인화된 캐릭터를 어떠한 존재로 인식하는지에 관한 탐구는 지극히 제한적이었다. 선행연구에 서 의인화된 캐릭터는 유아의 가상(환상)과 실재(현실) 구분 의 맥락에서 연구되었으며(Corriveau, Kim, Schwalen, \& Harris, 2009; Skolnick \& Bloom, 2006), 유아가 의인화된 캐릭터를 살 아있는 존재로 여기는지는 밝히지 못했다. 또한 유아의 생명 현상 인지에 관한 연구들은 유아가 생물범주와 비생물 범주를 구분할 수 있는지를 확인하기 위해 유아가 동물과 인공물을 
구분할 수 있는지(Gelman \& Gottfried, 1996; Massey \& Gelman, 1998)와 움직임이 없는 식물을 살아있다고 여기는지(Hatano \& Inagaki, 1994; Inagaki \& Hatano, 1996)에 주목해왔다.

유아가 생명현상을 인지할 수 있다고 보고한 연구들은 Piaget (1929)가 사용했던 개방형 질문보다 정교하고 대답하 기 쉬운 폐쇄형 질문을 사용하였다. '살아있다(alive)'라는 말 의 의미가 아동이 생각하는 것과 어른이 생각하는 것이 일치 하지 않을 수 있기 때문에(Carey, 1985), 살아있는지를 묻는 존재론적 구분은 아동의 이해를 포착해내기에 적합하지 않 을 수 있다. Inagaki와 Hatano (1996)는 '다람쥐와 악어는 죽을 수 있다. 그러면 튤립이나 소나무에게도 비슷한 일이 일어날 것 같니?'라고 질문하여 유아가 식물을 살아있는 존재로 인식 함을 밝혔다. 유아는 생리현상을 근거로 움직임이 없는 식물 에게도 생명이 있음을 인지할 수 있고, 5세와 6세 유아는 동 물과 식물은 모두 영양이 필요하고 성장한다는 것을 인식할 수 있다(Hatano \& Inagaki, 1994). 또한 유아는 자발적으로 움 직이는 동물과 인공물을 구별할 수 있으며, 동물은 내적 원인 에 의해 움직이고, 인공물은 배터리 같은 외적 원인에 의하여 움직인다는 것을 안다(Gelman \& Gottfried, 1996; Margett \& Witherington, 2011; Rakison \& Butterworth, 1998). 이러한 연구 결과를 종합해보면 Piaget (1929)가 제시했던 발달단계보다 유 아의 생명에 대한 이해 수준이 높지만 유아기 내에도 발달적 차이가 있는 것으로 보인다. 또한 살아있는지를 묻는 질문을 보완하여 폐쇄형 질문을 구성할 필요가 있다.

경계선적 대상인 로봇을 사용한 연구에서는 특성 추론 질 문을 통해 유아가 가지는 로봇에 대한 개념을 밝히고자 하였 다. 유아는 로봇이 생물특성은 가지고 있지 않지만 같이 놀 수 있고 감정을 지닌 존재로 인식하였다(Hyun \& Son, 2011). 또 한 운동성과 정서적 반응성이 다른 로봇에게 5 세 유아는 3세 유아보다 생물특성과 심리특성을 낮게(M. K. Kim, 2017; No \& Yi, 2017; Okita \& Schwartz, 2006), 행위자특성을 낮게(Okita $\&$ Schwartz, 2006), 그리고 인공물특성을 높게(No \& Yi, 2017) 추론하여 발달적 차이가 보고되었다. 이러한 최근의 연구들은 생물특성 추론과 심리특성 추론이 유사한 패턴을 보인다고 밝 힌 Carey (1985)의 연구결과와는 상반된다. 유아가 로봇이 생 물특성은 가지고 있지 않지만 심리특성은 가지고 있다고 추론 한 연구결과들은 유아가 모호한 대상의 속성을 추론할 때 단 일한 구분기준을 가지고 있지 않다는 것을 의미한다. 유아들 의 판단은 대상이 살아있는지, 생물특성이 있는지, 심리특성 이 있는지 묻는 질문에 따라 달라질 수 있다(Jipson \& Gelman, 2007). 따라서 본 연구에서도 선행연구에서 생명현상 추론을
살펴보기 위하여 생물적 특성과 정신적 특성을 묻는 질문을 사용했던 것처럼 생물특성과 심리특성을 묻는 질문들로 유아 의 추론 양상을 조사하였다.

의인화된 캐릭터는 허구적 존재이지만 애니메이션 속에서 생생히 살아서 움직이기 때문에 심리적으로 살아있다고 여겨 진다(Sung et al., 2004). 이러한 의인화된 캐릭터의 특성을 고 려할 때 의인화된 캐릭터가 유아에게 가상의 존재로 여겨지는 지 아니면 물리적인 실재로 여겨지는지를 확인할 필요가 있 다. 가상과 실재 구분에 관한 연구에서 유아는 성인이 명백히 가상의 존재라고 인식하는 산타클로스 등을 현실에 존재한다 고 여기도 한다(Clark, 1995). 하지만 일상생활 맥락에서 3세 유아도 장난감과 실제, 그림과 실제, 그리고 가장(pretending) 과 실제를 구분하여 말한다는 상반된 결과 역시 보고되었다 (Woolley \& Wellman, 1990). 누군가가 대상을 만질 수 있는지, 그 대상이 동시에 여러 곳에 나타날 수 있는지를 묻는 질문 을 통해 유아가 가상의 존재를 시공간의 제약을 받는 물리적 실체로 인식하는지 여부를 확인할 수 있다(Sharon \& Woolley, 2004). 본 연구에서도 가상의 존재인 의인화된 캐릭터가 유아 에게 물리적 실체로 인식되는지 알아보기 위해서 실재성 추론 문항을 구성하여 그 양상을 알아보았다.

유아는 성인이 될 때까지 지속적으로 의인화를 자발적이 고 일반적으로 사용한다. 유아는 어떤 대상이나 현상을 대할 때 그 대상이 인간과 비슷하다거나, 인간이 그 현상을 유발 했다고 생각한다(Guthrie, 1993). 유아는 대상을 인간의 특질 단서를 사용해서 인간으로 추론하고(Y. Park \& Yi, 2007), 사 물을 의인화하려는 경향이 있기 때문에 유아의 생명현상 인 지에서 대상의 의인화 정도가 영향을 미칠 수 있다. 의인화 (anthropomorphism)란 용어는 그리스어로 인간이란 뜻을 지닌 'anthropos'와 형태이라는 뜻을 지닌 'morphos'가 합하여 생성 된 말로, 인간이 아닌 동물, 사물, 자연현상 등에 인간의 특성 을 투사하는 것으로 정의된다(“anthropomorphism," n.d.). 애니 메이션에서 의인화된 캐릭터는 동기와 의도를 가지고 줄거리 를 이끌어가는 주인공으로, 시각적 표상을 통해 형체를 부여 받고 이야기의 맥락 안에 존재한다(Power, 2008). 즉, 의인화된 캐릭터는 인간의 속성을 부여받는 비인간 행위자로 애니메이 션에서 줄거리를 이끌어가는 주인공이다.

의인화된 동물 캐릭터의 의인화 수준은 동물에게 인간의 속성을 어느 정도 부여하는지를 통하여 구분된다. 의인화가 높을수록 캐릭터는 인간과 유사하고, 의인화가 낮을수록 캐 릭터는 동물과 유사하게 제시된다. 동물 캐릭터의 의인화 수 준은 Lee와 Kim (2009)의 연구에서 캐릭터의 외형적 형태, 제 
스처, 동작, 표정 등 비언어적 커뮤니케이션 특성이 얼마나 동 물적인지 혹은 인간적인지를 고려하여 구분되었다. 즉, 목소 리 및 표정의 의인화와 의복 및 액세서리 착용 등을 근거로 동 물형, 인간형, 혼합형으로 구분되었다. 구체적으로 살펴보면, 동물형은 동물의 골격을 유지하고 4족보행 등 동물적 습성을 지니는 것으로 동물에 가깝게 표현된 유형이다. 인간형은 완 전한 인간의 골격에 제스처와 훈련된 동작을 보이며, 옷을 입 고 장갑이나 신발 등 액세서리를 착용한 경우이다. 혼합형은 인간과 동물의 특성이 적당히 혼합된 중간 형태로 애니메이 션 동물 캐릭터에서 차지하는 비중이 가장 높다. 혼합형 캐릭 터는 목소리가 의인화되어 대화가 가능해지고, 표정이 의인 화되며, 앞발을 손처럼 사용하는 앞발의 구체적 제스처가 표 현된다. 동물 캐릭터의 의인화에 관한 또 다른 연구(S. N. Kim, 2003)에서는 인간처럼 옷 입기, 말하기, 행동하기를 기준으 로 ‘옷을 입지 않고 동물처럼 행동함, '옷을 입지 않고 동물처 럼 행동하면서 말함', '옷을 입지 않고 사람처럼 행동하면서 말 함', ‘옷을 입고 사람처럼 행동하면서 말함'으로 구분되었다. 본 연구에서는 동물 캐릭터의 의인화 정도의 차이가 유아에게 그 캐릭터가 살아있다고 인식되는지에 차이를 가져오는지 확 인하고자, 의복을 착용하지 않고 동물처럼 행동하면서 말을 하는 캐릭터(혼합형)와 의복과 액세서리를 착용하고 사람처 럼 행동하면서 말을 하는 캐릭터(인간형)를 선정하여 캐릭터 의 의인화 수준 차이가 유아의 인식에 미치는 영향을 알아보 았다.

의인화된 캐릭터는 애니메이션 영상 속에 존재하고 영상 을 통해서 인간에게 인식된다. 영상이라는 매체는 실제 존재 하는 대상을 녹화한 결과일 수도 있고, 작가의 상상 속에 존재 하는 대상을 시각화 기술을 통해 구현한 결과일 수도 있다. 의 인화된 캐릭터는 영상을 통해서만 전달가능하고, 영상은 실재 와 가상을 모두 표현할 수 있다는 점이 유아가 실재하지 않는 의인화된 캐릭터를 살아있다고 인지하게 만들 수 있다. 컴퓨 터 그래픽으로 창조한 영상은 실재하는 것이 무엇인지 혼동하 게 하는 리얼리즘의 문제를 제기할 수 있는데, 컴퓨터 그래픽 을 통해 실제 존재하지 않는 상황을 이미지화 할 수 있을 뿐만 아니라 사실적인 묘사를 통해 리얼리티를 확보할 수 있기 때 문이다(G. Jeon, 2010). 애니메이션은 현실을 모사하고자 하는 오랜 노력 끝에 현실보다 더 그럴듯한 가상세계를 만들어내며 환상과 현실의 경계를 허물고 있다(Rieh, 2005).

애니메이션에 적용된 컴퓨터 기술이 실재보다 더 실재 같 은 환영을 만들어 낼 수 있게 되면서(Rieh, 2005), 영상의 사실 성 차이가 의인화된 캐릭터에 대한 유아의 인식에 영향을 미
치는지를 확인할 필요가 있다. 일반적으로 의인화된 캐릭터는 $2 \mathrm{D}$ 혹은 $3 \mathrm{D}$ 애니메이션으로 표현된다. $2 \mathrm{D}$ 애니메이션은 종 이나 셀 등에 그린 그림을 연속 촬영하여 움직이는 장면을 만 드는 기법이고, 반면 $3 \mathrm{D}$ 애니메이션은 컴퓨터 기술을 바탕으 로 디지털 작업을 통해 사실적인 장면을 만드는 기법이다(M.J. Kim \& Kwak, 2017). 컴퓨터그래픽 기술의 발달로 실사 영화 와 애니메이션이 결합이 가능해졌는데(C. Park, 2014), 컴퓨터 그래픽 이미지로 사실적으로 표현된 의인화된 캐릭터가 실사 영화의 현실적인 배경에서 제시될 수 있는 것이다. $2 \mathrm{D}$ 애니메 이션과 실사영화라는 의인화된 캐릭터가 제시되는 맥락의 차 이 및 $3 \mathrm{D}$ 기술을 통해 의인화된 캐릭터가 사실적으로 표현되 는 것이 의인화된 캐릭터에 대한 생명현상 인지 및 추론에 영 향을 미치는지 확인할 필요가 있다.

본 연구에서는 생명현상 인지에서 경계선적 대상이 중요함 에도 의인화된 캐릭터에 대한 유아의 생명현상 인지가 선행연 구에서 충분히 다루어지지 못한 것에 주목하여 캐릭터의 의인 화 수준과 영상의 사실성 정도에 따라 유아의 생명현상 인지 및 생명현상 추론이 달라지는 살펴보고자 하였으며, 이와 같 은 연구의 목적에 근거하여 다음과 같은 연구 문제를 선정하 였다.

\section{연구문제 1}

의인화된 캐릭터에 대한 유아의 생명현상 인지는 유아의 연령 $(3,4,5$ 세 $)$ 에 따라 유의한 차이가 있는가?

\section{연구문제 2}

의인화된 캐릭터에 대한 유아의 생명현상 추론은 유아의 연령 $(3,4,5$ 세)과 대상의 속성(의인화, 사실성)에 따라 유의한 차 이가 있는가?

\section{연구방법}

\section{연구 참여자}

본 연구에서는 서울과 경기도의 어린이집 두 곳에서 언어와 인지에 문제가 없는 3, 4, 5세 유아 95명을 참여자로 선정하였 다. 의인화된 캐릭터(가필드, 스튜어트 리틀)에 대한 사전경험 이 의인화된 캐릭터에 대한 인식과 이해에 영향을 미칠 수 있 기 때문에, 사전경험이 있는 8 명의 응답을 제외하고 분석하였 다. 참여 유아의 평균 월령은 만 3세 41개월, 만 4세 53.19개월, 
만 5세 64.45개월로 나타났다. 연구 대상 유아의 연령, 월령, 그리고 성별은 Table 1 과 같다.

Table 1

Age and Gender of the Participants

\begin{tabular}{ccccc}
\hline & \multirow{2}{*}{$\begin{array}{c}\text { Mean age in month } \\
\text { Age }\end{array}$} & \multicolumn{2}{c}{ Gender $(n)$} & \\
\cline { 3 - 4 } 3 & $41.00(36-47)$ & 17 & 14 & 31 \\
4 & $53.19(48-59)$ & 13 & 18 & 31 \\
5 & $64.45(60-71)$ & 18 & 15 & 33 \\
Total & $53.13(36-71)$ & 48 & 47 & 95 \\
\hline
\end{tabular}

\section{연구도구}

\section{의인화된 캐릭터 영상의 구성}

의인화된 캐릭터는 Figure 1 에서 보는 것과 같이 의인화와 사 실성 수준에 따라 4 개로 제시하였다. 의인화 수준은 Lee와 $\operatorname{Kim}$ (2009)및 S. N. Kim (2003)의 연구에서 사용한 기준을 참 고하여 구분되었다. 의인화 수준이 낮은 캐릭터(혼합형)로 '가 필드'를 선정하였다. 가필드는 목소리와 표정은 의인화되었지 만 옷을 입지 않고 동물처럼 행동하면서 말을 한다. 한편, 의인 화 수준이 높은 캐릭터(인간형)로 '스튜어트 리틀'을 선정하였
다. 스튜어트 리틀은 옷을 입고 신발을 신고 있으며 사람처럼 말과 행동을 한다. 사실성 수준은 영상의 종류에 따라 구분되 었다. 사실성 수준이 낮은 의인화된 캐릭터는 $2 \mathrm{D}$ 애니메이션 의 맥락에서 만화의 주인공으로 제시되었다. 한편, 사실성 수 준이 높은 의인화된 캐릭터는 실사영화의 맥락에서 $3 \mathrm{D}$ 방식 으로 제작되어 영화의 주인공으로 제시되었다.

본 연구에서 의인화된 캐릭터로 가필드와 스튜어트 리틀을 선정하면서 다음의 두 가지를 고려하였다. 먼저 두 캐릭터는 각각 고양이와 쥐를 의인화한 것으로, 고양이와 쥐는 모두 유 아에게 친숙하고 동화책 등에서 자주 접할 수 있는 동물일 뿐 만 아니라 강아지, 곰과 함께 애니메이션 캐릭터로 가장 자주 등장하는 동물이라는 점(Lee, Hong, \& Kim, 2010)이 고려되었 다. 또한 두 캐릭터는 의인화 수준이 다를 뿐 아니라 애니메이 션과 실사영화로 제작되어 사실성 비교가 가능하기 때문에 본 연구에서 알아보고자 하는 의인화된 캐릭터의 속성을 지니고 있어 선정되었다.

본 연구에서 사용한 네 가지 영상은 각각 다음과 같다. 의인 화와 사실성 수준이 모두 낮은 것으로 미국 CBS 방송에서 방 영된 Garfield and Friends (1988-1994년) 애니메이션, 의인화 수준 낮고 사실성 수준 높은 것으로 2004년 개봉한 'Garfield: The Movie' 실사영화, 의인화 수준 높고 사실성 수준 낮은 것 으로 2005년 개봉한 'Stuart Little 3: Call of the Wild' 애니메이

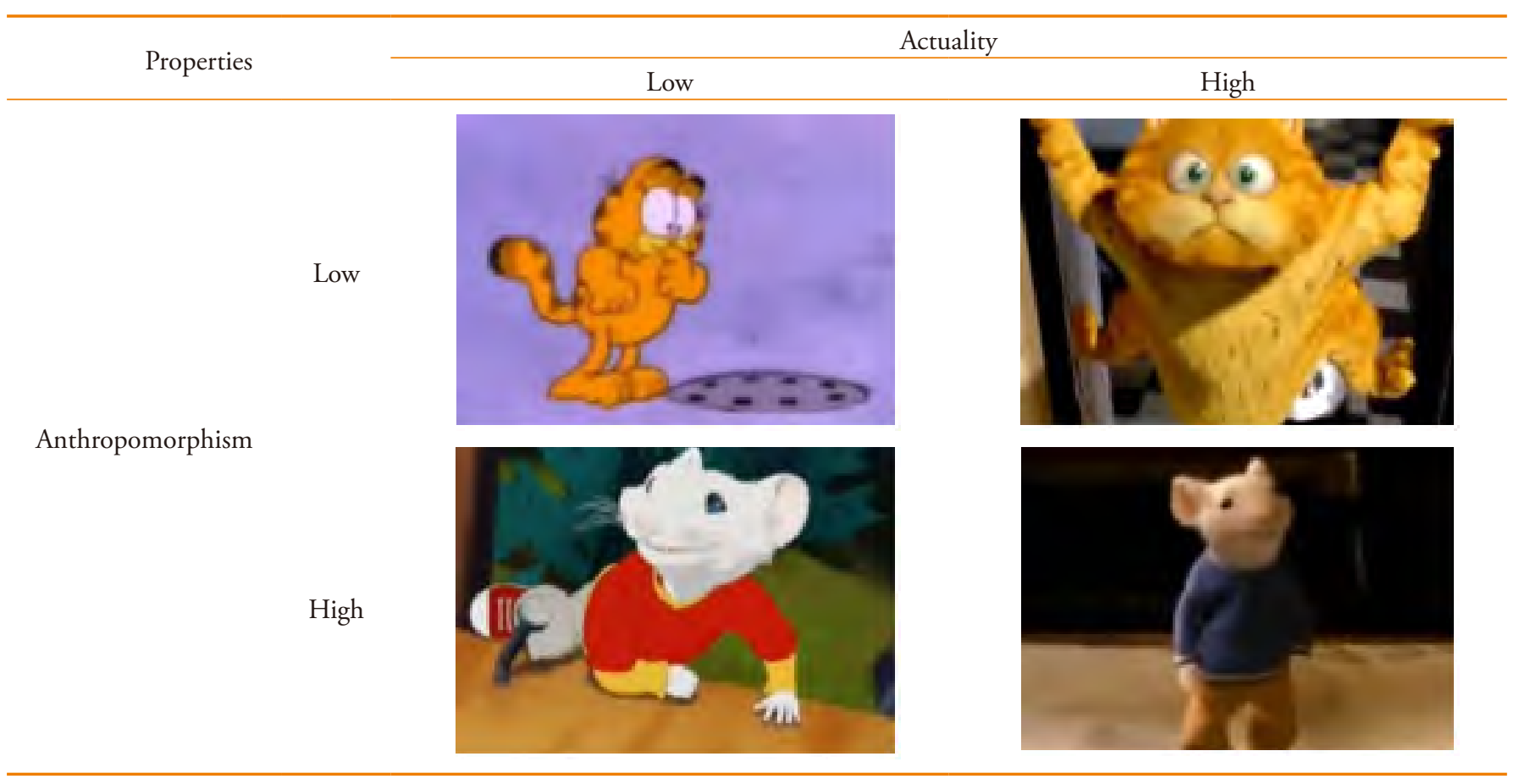

Figure 1. Properties of anthropomorphic characters. 
션, 의인화 수준 높고 사실성 수준 높은 것으로 1999 년 개봉한 ‘Stuart Little' 실사영화를 사용하였다. 개별영상은 녹화프로그 램에 의해 녹화 및 편집되어 유아에게 각각 30 초 간 제시되었 다. 영상의 녹화 및 편집 기준은 등장인물로 주인공 애니메이 션 캐릭터(가필드, 스튜어트 리틀)만 나오면서 애니메이션 캐 릭터의 의인화 및 사실성 차이가 드러나는 것이다. 즉 영상은 캐릭터의 전체적인 외양 및 동작이 잘 드러나는 장면과 표정 과 제스처가 잘 드러나는 장면들을 편집하여 구성하였다. 또 한 생명현상 추론과제에서 사용하는 생물특성, 심리특성, 실 재성이 직접적으로 드러나지 않는 장면이 선택되었고, 서로 다른 배경음이 주는 영향을 차단하기 위해 의인화된 캐릭터의 영상은 음이 소거된 채로 상영되었다.

\section{생명현상 인지 및 추론 과제}

본 연구에서는 영상으로 의인화된 캐릭터를 제시한 후 유아에 게 “이것은 살아있는 것 같아요?”라고 질문하여 의인화된 캐 릭터에 대한 유아의 생명현상을 인지를 확인하였다. 의인화 된 캐릭터에 대한 유아의 생명현상 추론은 세 가지 하위 특성 에 관한 폐쇄형 질문을 통하여 확인하였다. 연구자가 생명현 상의 하위 항목인 생물특성, 심리특성, 실재성이 제시된 의인 화된 캐릭터에 있는지 묻고 유아는 '예’ 혹은 '아니요'로 응답 하여 유아의 생명현상 추론을 알아보았다. 생물특성은 생물이 공통적으로 가지고 있는 생리적 특성을 의미하며, 구체적으로 성장, 섭취, 치유, 번식을 묻는 문항으로 구성되었다. 심리특성 은 정서와 인지적 특성을 의미하며, 대상이 행복감이나 분노 를 느낄 수 있는지, 집을 찾고 생각을 할 수 있는지를 묻는 문 항으로 구성되었다. 실재성은 대상이 물리적 실체가 있는 존 재인지에 관한 것으로, 볼 수 있고, 들을 수 있고, 만질 수 있는 지를 묻는 문항으로 구성되었다. 추론과제에서 사용하는 질문 은 Jipson과 Gelman (2007), Sharon과 Woolley (2004)의 연구에 서 사용된 질문을 중심으로 구성하였으며, 유아가 질문에 '예' 라고 응답한 경우에 1점을 부여하였다. 각 범주 별 만점은 생 물특성 4점, 심리특성 4점, 그리고 실재성은 3점으로, 점수가 높을수록 유아는 제시된 대상의 생물특성, 심리특성, 그리고 실재성을 높게 인지하고 있음을 나타낸다. 본 연구에서 사용 한 질문의 구체적 내용은 Table 2 와 같다.

\section{연구절차}

이 연구는 서울대학교 생명윤리위원회의 승인 이후 연구 참여
Table 2

Categories and Questions of Inferencing of Life Phenomenon

\begin{tabular}{|c|c|c|}
\hline Category & Questions & Scores \\
\hline Biological trait & $\begin{array}{l}\text { Does this grow? } \\
\text { Does this need water? } \\
\text { Is this cured after injury? } \\
\text { Can this have a baby? }\end{array}$ & $0-4$ \\
\hline Psychological trait & $\begin{array}{l}\text { Does this feel happy? } \\
\text { Does this fight when angry? } \\
\text { Can this find its home? } \\
\text { Can this think? }\end{array}$ & $0-4$ \\
\hline Reality & $\begin{array}{l}\text { Can anyone see this? } \\
\text { Can anyone touch this? } \\
\text { Can anyone hear the voice of this? }\end{array}$ & $0-3$ \\
\hline
\end{tabular}

자 모집 및 조사가 이루어졌다(IRB No. 1310/001-009). 조사는 연구자 및 아동학 전공자 3 인에 의해 실시되었고 조사원은 사 전에 과제와 연구윤리에 관한 안내를 받은 후 조사에 임하였 다. 2013년 10월 서울과 경기도의 어린이집 두 곳에서 조사가 이루어졌고, 어린이집 내의 조용한 장소에서 약 10 분 정도의 일대일 면접으로 자료가 수집되었다. 조사원은 유아를 만나 인사를 나누고 간단한 대화를 나누며 라포를 형성하였다. 영 상을 제시하기 전 유아에게 선생님이 만화를 보여줄 것이고, 보고 나서 선생님이 묻는 질문을 듣고 유아의 생각을 이야기 해달라고 하였다. 영상은 의인화 캐릭터의 속성 크기에 따라 일정한 순서(의인화와 사실성이 모두 낮은 영상-의인화 낮고 사실성 높은 영상-의인화 높고 사실성 낮은 영상-의인화와 사 실성 모두 높은 영상)로 제시한 후 생명현상 인지과제와 추론 과제를 진행하였다. 연구자는 유아의 응답을 바로 인터뷰 결 과표에 표시하였으며, 유아가 대답을 망설일 경우에는 두 번 더 물어보고 다음 문항으로 넘어갔다.

\section{자료 분석}

수집한 자료는 PASW 18.0 (SPSS Inc., Chicago, IL)프로그램을 이용하여 분석하였다. 의인화된 캐릭터에 대한 유아의 생명현 상 인지가 유아의 연령에 따라 차이가 있는지 알아보기 위하 여 카이제곱 검정 $\left(\chi^{2}\right.$-test)을 실시하였다. 다음으로 연령과 대 상의 속성에 따라 유아의 생명현상 추론에 차이가 있는지 알 아보기 위하여 반복측정변량분석(repeated measures ANOVA) 을 실시하였다. 본 연구에서는 연령을 개체 간 변인으로, 의인 화된 캐릭터의 속성을 개체 내 변인으로 설정하여 $3 \times 4$ 분할 구획요인으로 설계하였다. 이 경우 반복측정변량분석을 통해 유아의 생명현상 추론에서 연령에 따른 차이(개체 간)와 의인 
Table 3

Differences of Cognition of Life Phenomenon According to Infants' Age

\begin{tabular}{llcccc}
\hline & & \multicolumn{5}{c}{ Properties of anthropomorphic characters } \\
\cline { 3 - 6 } Age & $n$ & $\begin{array}{c}\text { Low anthropomorphism } \\
\text { \& Low actuality }\end{array}$ & $\begin{array}{c}\text { Low anthropomorphism } \\
\text { \& High actuality }\end{array}$ & $\begin{array}{c}\text { High anthropomorphism } \\
\text { \& Low actuality }\end{array}$ & $\begin{array}{c}\text { High anthropomorphism } \\
\text { \& High actuality }\end{array}$ \\
\hline 3 & 31 & $26(83.9)$ & $27(87.1)$ & $26(83.9)$ & $24(77.4)$ \\
4 & 31 & $27(87.1)$ & $28(90.3)$ & $27(87.1)$ & $23(74.2)$ \\
5 & 33 & $30(90.9)$ & $30(90.9)$ & $29(87.9)$ & $29(87.9)$ \\
Total & 95 & $83(87.4)$ & $85(89.5)$ & $82(86.3)$ & $76(80.0)$ \\
\multicolumn{2}{c}{$\chi^{2}(d f)$} & $.72(2)$ & $.28(2)$ & $.24(2)$ & $2.06(2)$ \\
\hline
\end{tabular}

Note. Unit $=N(\%)$.

Table 4

Means and Standard Deviations of Variables (Inference of Biological Traits)

\begin{tabular}{llcccc}
\hline & & \multicolumn{4}{c}{ Properties of anthropomorphic characters } \\
\cline { 3 - 6 } Age & $n$ & $\begin{array}{c}\text { Low anthropomorphism } \\
\text { \& Low actuality }\end{array}$ & $\begin{array}{c}\text { Low anthropomorphism } \\
\text { \& High actuality }\end{array}$ & $\begin{array}{c}\text { High anthropomorphism } \\
\text { \& Low actuality }\end{array}$ & $\begin{array}{c}\text { High anthropomorphism } \\
\text { \& High actuality }\end{array}$ \\
\hline 3 & 31 & $3.48(.93)$ & $3.52(.96)$ & $3.26(1.00)$ & $3.19(1.22)$ \\
4 & 30 & $2.83(1.44)$ & $3.17(1.12)$ & $2.47(1.46)$ & $2.80(1.47)$ \\
5 & 33 & $3.00(1.23)$ & $3.12(1.22)$ & $2.76(1.39)$ & $2.82(1.26)$ \\
Total & 94 & $3.11(1.23)$ & $3.27(1.11)$ & $2.83(1.33)$ & $2.94(1.32)$ \\
\hline
\end{tabular}

Note. Unit $=N(\%)$.

화된 캐릭터 속성에 따른 차이(개체 내)를 구분하여 알 수 있 다. 개체 간 차이가 유의한 경우 Scheffé 사후검정, 개체 내 차 이가 유의한 경우 Helmert 대비검정을 실시하였다.

\section{연구결과}

\section{유아의 연령에 따른 의인화된 캐릭터에 대한 생명현상 인지}

유아의 연령에 따라서 의인화와 사실성 수준이 다른 의인화된 캐릭터에 대한 생명현상 인지에 차이가 있는지 카이제곱 검정 을 실시한 결과 유아의 연령에 따른 차이가 유의하지 않았다 (Table 3). 제시된 대상이 살아있는 것 같다고 응답한 유아의 비 율을 의인화된 캐릭터의 속성별로 살펴보면 다음과 같다. 의 인화와 사실성이 모두 낮은 캐릭터가 살아있다는 응답은 3세 $83.9 \%, 4$ 세 $87.1 \%, 5$ 세 $90.0 \%$ 로 나타났다. 의인화는 낮고 사 실성이 높은 캐릭터의 경우 3세 $87.1 \%, 4$ 세 $90.3 \%, 5$ 세 $90.9 \%$ 가 살아있는 것 같다고 응답하였다. 의인화가 높고 사실성이 높은 캐릭터가 살아있다는 응답은 3세 $83.9 \%, 4$ 세 $87.1 \%, 5$ 세 $87.9 \%$ 로 나타났다. 의인화와 사실성이 모두 높은 캐릭터의 경
우 3세 $77.4 \%, 4$ 세 $74.2 \%, 5$ 세 $87.9 \%$ 가 살아있는 것 같다고 응 답하였다. 제시된 의인화된 캐릭터가 살아있는 것 같은지 묻는 질문에 $3,4,5$ 세 유아 모두 비교적 높은 수준으로 살아있는 것 같다고 응답하였고, 통계적으로 유의하지 않았지만 3세와 4세 보다 5세의 살아있다는 응답비율이 더 높았다.

\section{유아의 연령과 의인화된 캐릭터의 속성에 따른 생명현상 추론}

\section{의인화된 캐릭터에 대한 생물특성 추론}

유아의 연령에 따른 의인화된 캐릭터에 대한 생물특성 추론 양상은 Table 4 와 같다. 유아는 의인화와 사실성이 모두 낮은 캐릭터의 생물특성을 3 세 3.38점 $(S D=.93), 4$ 세 2.83점 $(S D=$ $1.44), 5$ 세 3.00점 $(S D=1.23)$ 으로 추론하였다. 또한 의인화와 사실성이 모두 높은 캐릭터의 경우 생물특성을 3세 3.19점( $S D$ $=1.22), 4$ 세 2.80점 $(S D=1.47), 5$ 세 2.82점 $(S D=1.26)$ 으로 추 론하였다. 이러한 결과는 3 세가 4 세와 5 세보다 의인화된 캐릭 터의 생물특성을 높게 추론하고, 캐릭터의 의인화와 사실성 수준이 높은 경우보다 낮은 경우 유아가 생물특성을 더 높게 추론하고 있음을 보여준다. 
Table 5

Results of Repeated Measures ANOVA (Inference of Biological Traits)

\begin{tabular}{|c|c|c|c|c|c|}
\hline Source & SS & $d f$ & $M S$ & $F$ & Helmert \\
\hline Between factor & 437.30 & 93 & & & \\
\hline Age & 20.67 & 2 & 10.34 & 2.26 & \\
\hline Within factor & 153.39 & 282 & & & \\
\hline Properties of anthropomorphic characters & 10.51 & 3 & 3.20 & $6.79^{* * *}$ & $a, b>c, d$ \\
\hline Error & 140.71 & 273 & .52 & & \\
\hline
\end{tabular}

Note. $\mathrm{a}=$ low anthropomorphism \& low actuality character, $\mathrm{b}=$ low anthropomorphism \& high actuality character, $\mathrm{c}=$ high anthropomorphism $\&$ low actuality character, $\mathrm{d}=$ high anthropomorphism $\&$ high actuality character

*** $p<.001$.

Table 6

Means and Standard Deviations of Variables (Inference of Psychological Traits)

\begin{tabular}{llcccc}
\hline & & \multicolumn{4}{c}{ Properties of anthropomorphic characters } \\
\cline { 3 - 6 } Age & $n$ & $\begin{array}{c}\text { Low anthropomorphism } \\
\text { \& Low actuality }\end{array}$ & $\begin{array}{c}\text { Low anthropomorphism } \\
\text { \& High actuality }\end{array}$ & $\begin{array}{c}\text { High anthropomorphism } \\
\text { \& Low actuality }\end{array}$ & $\begin{array}{c}\text { High anthropomorphism } \\
\text { \& High actuality }\end{array}$ \\
\hline 3 & 31 & $3.55(.81)$ & $3.42(1.12)$ & $3.35(1.05)$ & $3.35(1.08)$ \\
4 & 30 & $3.27(1.23)$ & $3.33(1.18)$ & $3.13(1.25)$ & $2.93(1.41)$ \\
5 & 33 & $3.06(1.32)$ & $3.06(1.25)$ & $3.03(1.38)$ & $3.00(1.20)$ \\
Total & 94 & $3.29(1.15)$ & $3.27(1.18)$ & $3.17(1.23)$ & $3.10(1.24)$ \\
\hline
\end{tabular}

Note. Unit $=N(\%)$.

위에서 살펴본 유아의 생물특성 추론의 차이가 통계적으로 유의한 차이인지 확인하기 위하여 유아의 연령과 의인화된 캐 릭터의 속성에 따라 생물특성 추론에 유의한 차이가 있는지 반복측정변량분석을 실시하였다. Table 5에 제시된 것과 같이, 연령에 따른 생물특성 추론의 차이는 유의하지 않았지만, 의 인화된 캐릭터의 속성에 따른 생물특성 추론의 차이는 유의하 였다 $(F=6.79, d f=3,273, p<.001)$. 이를 구체적으로 살펴보기 위해 Helmert 대비검정을 실시한 결과 유아는 의인화 수준이 높은 캐릭터보다 의인화 수준이 낮은 캐릭터의 생물특성을 더 높게 추론하였다. 이러한 결과는 $3,4,5$ 세 유아에게 의인화 수 준이 낮은 캐릭터가 의인화 수준이 높은 캐릭터보다 성장, 섭 취, 재생, 번식 등의 생물특성을 더 많이 가지고 있다고 인식되 고 있음을 나타낸다.

\section{의인화된 캐릭터에 대한 심리특성 추론}

유아의 연령에 따른 의인화된 캐릭터에 대한 심리특성 추론 양상은 Table 6과 같다. 유아는 의인화와 사실성이 모두 낮은
캐릭터의 심리특성을 3세 3.55점 $(S D=.81)$, 4세 3.27점 $(S D=$ $1.23)$, 5세 3.06점 $(S D=1.32)$ 으로 추론하였다. 또한 의인화와 사실성이 모두 높은 캐릭터의 경우 심리특성을 3세 3.35점(SD $=1.08), 4$ 세 2.93점 $(S D=1.41), 5$ 세 3.00점 $(S D=1.24)$ 으로 추 론하였다. 이러한 결과는 3 세가 4 세와 5 세보다 의인화된 캐릭 터의 심리특성을 높게 추론하고, 캐릭터의 의인화와 사실성 수준이 높은 경우보다 낮은 경우 유아가 심리특성을 더 높게 추론하고 있음을 보여준다.

위에서 살펴본 유아의 심리특성 추론의 차이가 통계적으로 유의한 차이인지 확인하기 위하여 유아의 연령과 의인화된 캐 릭터의 속성에 따라 심리특성 추론에 유의한 차이가 있는지 반복측정변량분석을 실시하였다. Table 7에 제시된 것과 같이, 유아의 연령에 따른 차이 및 대상의 속성에 따른 심리특성 추 론의 차이는 통계적으로 유의하지 않았다.

\section{의인화된 캐릭터에 대한 실재성 추론}

유아의 연령에 따른 의인화된 캐릭터에 대한 실재성 추론 양 
상은 Table 8 과 같다. 유아는 의인화와 사실성이 모두 낮은 캐 릭터의 실재성을 3세 2.71점 $(S D=.69)$, 4세 2.47점 $(S D=.97), 5$ 세 1.97 점 $(S D=1.13)$ 으로 추론하였다. 또한 의인화와 사실성 이 모두 높은 캐릭터의 경우 실재성을 3세 2.55점 $(S D=.93), 4$ 세 2.07점 $(S D=1.14)$, 5세 1.79점 $(S D=1.29)$ 으로 추론하였다. 이러한 결과는 3 세보다 4 세, 4 세보다 5 세가 의인화된 캐릭터 의 실재성을 낮게 추론하고, 캐릭터의 의인화와 사실성 수준 이 낮은 경우 보다 높은 경우 유아가 실재성을 더 낮게 추론하
고 있음을 보여준다.

위에서 살펴본 유아의 실재성 추론이 통계적으로 유의한 차이인지 확인하기 위하여 유아의 연령과 의인화된 캐릭터의 속성에 따라 실재성 추론에 유의한 차이가 있는지 반복측정변 량분석을 실시하였다. Table 9에 제시된 것과 같이, 유아의 연 령에 따른 차이가 유의하였다 $(F=7.78, d f=2,91, p<.01)$. 연 령의 주효과를 구체적으로 확인하기 위해 Scheffé 사후검정을 실시한 결과 3 세 유아와 5 세 유아의 차이가 유의하였다. 즉, 3

Table 7

Results of Repeated Measures ANOVA (Inference of Psychological Traits)

\begin{tabular}{lrrrr}
\hline \multicolumn{1}{c}{ Source } & \multicolumn{1}{c}{$S S$} & $d f$ & $M S$ & $F$ \\
\hline Between factor & 415.98 & 93 & & \\
$\quad$ Age & 9.56 & 2 & 4.78 & 1.07 \\
Error & 406.42 & 91 & 4.47 & \\
Within factor & 123.36 & 282 & & .78 \\
$\quad$ Properties of anthropomorphic characters & 2.33 & 3 & .24 & 1.77 \\
$\quad$ Properties of anthropomorphic characters $\times$ Age & 1.44 & 6 & & .55 \\
Error & 119.59 & 273 & \\
\hline
\end{tabular}

Table 8

Means and Standard Deviations of Variables (Inference of Reality)

\begin{tabular}{llcccc}
\hline & & \multicolumn{4}{c}{ Properties of anthropomorphic characters } \\
\cline { 3 - 6 } Age & $n$ & $\begin{array}{c}\text { Low anthropomorphism } \\
\text { \& Low actuality }\end{array}$ & $\begin{array}{c}\text { Low anthropomorphism } \\
\text { \& High actuality }\end{array}$ & $\begin{array}{c}\text { High anthropomorphism } \\
\text { \& Low actuality }\end{array}$ & $\begin{array}{c}\text { High anthropomorphism } \\
\text { \& High actuality }\end{array}$ \\
\hline 3 & 31 & $2.71(.69)$ & $2.71(.64)$ & $2.55(.93)$ & $2.55(.93)$ \\
4 & 30 & $2.47(.97)$ & $2.53(.94)$ & $2.20(1.13)$ & $2.07(1.14)$ \\
5 & 33 & $1.97(1.13)$ & $1.76(1.28)$ & $1.70(1.16)$ & $1.79(1.29)$ \\
Total & 94 & $2.37(.99)$ & $2.32(1.07)$ & $2.14(1.12)$ & $2.13(1.17)$ \\
\hline
\end{tabular}

Note. Unit $=N(\%)$.

Table 9

Results of Repeated Measures ANOVA (Inference of Reality)

\begin{tabular}{|c|c|c|c|c|c|}
\hline Source & SS & $d f$ & $M S$ & $F$ & $\begin{array}{l}\text { Scheffé } \\
\text { Helmert }\end{array}$ \\
\hline Between factor & 76.49 & 93 & & & \\
\hline Age & 11.17 & 2 & 5.59 & $7.78^{* *}$ & $a>b$ \\
\hline Error & 65.32 & 91 & & & \\
\hline Within factor & 126.24 & 282 & & & \\
\hline Properties of anthropomorphic characters & 4.51 & 3 & 1.50 & $3.07^{*}$ & $c>d, e, f$ \\
\hline Properties of anthropomorphic characters $\times$ Age & 2.14 & 6 & .36 & .73 & \\
\hline Error & 119.59 & 273 & & & \\
\hline
\end{tabular}

Note. $\mathrm{a}=3$ years, $\mathrm{b}=5$ years, $\mathrm{c}=$ low anthropomorphism $\&$ low actuality character, $\mathrm{d}=$ low anthropomorphism $\&$ high actuality character, $\mathrm{e}=$ high anthropomorphism $\&$ low actuality character, $\mathrm{f}=$ high anthropomorphism \& high actuality character

${ }^{*} p<.05 .{ }^{* *} p<.01$. 
세 유아는 5세 유아보다 의인화된 캐릭터의 실재성을 높게 추 론하였다. 이러한 결과는 5세 유아는 3세 유아에 비하여 의인 화된 캐릭터가 볼 수 없고, 만질 수 없고, 소리를 들을 수 없는 가상의 존재라는 사실을 인식하고 있다는 것을 의미한다.

실재성 추론에서 의인화된 캐릭터의 속성에 따른 차이 역 시 유의하였다 $(F=3.07, d f=3,273, p<.05)$. 구체적인 양상을 알아보기 위해 Helmert 대비검정 결과 의인화와 사실성이 낮 은 캐릭터와 나머지 의인화된 캐릭터의 차이가 유의하였다. 이러한 결과는 유아가 의인화와 사실성이 낮은 캐릭터를 속성 이 다른 나머지 의인화된 캐릭터에 비하여 볼 수 있고, 만질 수 있고, 소리를 들을 수 있는 실재하는 존재로 인식하고 있음을 나타낸다.

\section{논의 및 결론}

본 연구는 물리적으로 실재하지 않지만 심리적으로 살아있다 고 여겨지는 의인화된 캐릭터가 유아에게 어떻게 인지되는지 가 선행연구에서 충분히 다루어지지 않은 점에 주목하여, 캐릭 터의 의인화와 사실성 수준을 달리하여 유아의 생명현상 인지 및 추론 양상을 알아보고자 하였다. 유아의 연령에 따라 의인 화와 사실성 수준이 다른 의인화된 캐릭터에 대한 유아의 생명 현상 인지에 차이가 있는지, 그리고 유아가 생물특성, 심리특 성, 실재성을 추론하는 양상이 다른지를 알아보고자 하였다.

위와 같은 연구 목적에 의하여 본 연구에서는 $3,4,5$ 세 총 95명의 유아를 대상으로 생명현상 인지 및 추론과제를 실시 하였으며, PASW 프로그램을 이용하여 분석된 결과를 바탕으 로 다음과 같은 결론을 도출하였다. 첫째, $3,4,5$ 세 유아는 의 인화된 동물 캐릭터를 동물로 인지한다. 본 연구에서 의인화 된 캐릭터가 살아있는지 묻는 질문에 3, 4, 5세 유아 모두 높 은 비율로 살아있다고 응답하였다. 또한 유아는 연령에 상관 없이 의인화된 캐릭터의 생물특성을 비교적 높은 수준으로 추 론하였다. 의인화는 캐릭터에 생동감과 실재감을 부여하는 과 정으로(Lee, Kim, \& Kim, 2015), 의인화를 통해 캐릭터는 애 니메이션 속에서 사람처럼 생각하고 느끼고 말하며 행동한 다. 캐릭터는 의인화되어 실제 동물과 다르고 인간에 가깝게 제시되었지만 유아는 이러한 캐릭터를 동물이라고 여긴 것이 다. 영유아가 외양이나 재질과 같은 대상의 지각적 특성을 근 거로 대상이 살아있는지 여부를 판단한다는 연구 결과(Jones, Smith, \& Landau., 1991; Rakison \& Butterworth., 1998)를 고려 할 때, 캐릭터가 의인화 된 것보다는 고양이나 쥐 같은 동물이
라는 점이 더 우세하게 인지된 것으로 해석할 수 있다. 이는 의 인화된 캐릭터가 동물에 인간의 모습을 더 한 것이지만 일반 적으로 인간의 얼굴보다는 동물에 가깝게 인식된다는 연구결 과(Lee et al., 2010)와 일치하는 결과이다. 또한 영상이 외부의 대상을 있는 그대로가 아니라 변형하여 제시할 수 있다는 사 실을 유아가 알지 못할 수 있다(Cho \& Yi, 2002; Flavell, Flavell, Green, \& Korfmacher, 1990)는 점을 고려할 때, 의인화된 캐릭 터가 유아에게 현실에 있는 동물의 재현으로 인식된 것으로 보인다. 즉 의인화된 캐릭터는 유아에게 동물로 인지되어, 생 물의 특성을 가지고 있는 살아있는 존재로 인식되었다.

둘째, 캐릭터의 의인화 수준에 따라 유아의 생물특성 추론 양상이 다르며, 의인화 수준이 낮은 캐릭터가 생물특성을 더 많이 가지고 있는 것으로 여겨진다. 구체적으로 살펴보면, 유 아는 의인화 수준이 낮은 혼합형 캐릭터가 의인화 수준이 높 은 인간형 캐릭터보다 몸이 자라고, 물이 필요하고, 자기와 닮 은 새끼를 낳을 수 있는 것 같은 생물특성을 더 많이 가지고 있 을 것이라 여겼다. 본 연구에서 캐릭터의 의인화 수준은 의복 과 장신구 착용여부 및 행동 특성에 의해 구분되었다. 즉 의인 화 수준이 낮은 캐릭터(혼합형)는 의복과 장신구를 하지 않고 동물과 같이 행동하고, 의인화 수준이 높은 캐릭터(인간형)는 의복과 장신구를 하고 두 발로 서서 인간과 같이 행동한다. 아 동의 생명 개념은 '생각한다', '말소리를 내고 듣는다'와 같이 인간위주 개념과, '움직인다', '숨쉰다'와 같이 동물 위주 개념 이 동시에 나타나지만, 동물 위주의 개념이 더욱 우세하다는 연구결과(M.-J. Kim, 2008)를 고려할 때, 의인화 수준이 낮은 혼합형 캐릭터가 인간형 캐릭터에 비해 아동이 지닌 생명개념 에 더욱 부합하여 생물이 보이는 특성을 많이 가지고 있다고 여겨진 것으로 보인다. 유아가 동물 캐릭터의 의인화 수준에 따라 그 캐릭터에게 생물의 특성을 어느 정도 부여하는지에 대한 추가적인 연구가 필요하다.

셋째, $3,4,5$ 세 유아는 의인화된 캐릭터를 심리적 실재로 여긴다. 의인화된 캐릭터는 물리적으로는 실재하지 않는 허 구적 존재이지만 이야기 속에 동기와 의도를 가지고 줄거리 를 이끌어가도록 고안되었다(Power, 2008). 이러한 가상의 존 재인 의인화된 캐릭터가 심리적으로는 살아있는 실재처럼 여 겨지는 지 알아본 결과 유아는 의인화된 캐릭터의 심리특성을 높은 수준으로 추론하였다. 즉, 유아의 연령 및 의인화된 캐릭 터의 속성에 상관없이 유아는 의인화된 캐릭터가 행복이나 분 노를 느끼는 정서적 존재이자, 집을 찾을 수 있고 생각도 할 수 있는 인지적 존재로 여기고 있었다. 이러한 결과는 의인화된 캐릭터가 성인에게 친근한 사람처럼 지각되고 추억과 같은 긍 
정적인 정서를 유발했다는 연구 결과(Sung et al., 2004)와 마찬 가지로 유아에게도 친근하고 정서적인 존재로 여겨졌음을 의 미한다. 또한 로봇과 같이 물리적 실재임에는 분명하지만 심 리적 실재로 여겨지는지 모호한 대상을 유아가 말을 이해하고 감정을 표현하는 존재(Hyun \& Son, 2011)이자 정서가 있고 사 고를 할 수 있는 존재(M. K. Kim, 2017; No \& Yi, 2017)로 인식 했다는 연구결과를 고려할 때, 의인화된 캐릭터는 가상의 존 재이지만 유아에게 심리적 특성을 가진 존재로 인지되는 것으 로 보인다.

넷째, 높은 연령의 유아는 의인화된 캐릭터가 현실에 존재 하지 않는 허구적 존재임을 인지한다. 5 세 유아는 3세 유아보 다 의인화된 캐릭터의 실재성을 유의하게 낮게 추론하였는데, 이는 5세 유아는 의인화된 캐릭터가 실제로 볼 수 없고, 소리 를 들을 수 없고, 만질 수 없는 가상의 존재라는 사실을 알고 있음을 뜻한다. 이러한 결과는 4 세와 5 세 유아가 가상과 실제 존재의 물리적 특성을 다르게 추론했으며 그 양상이 성인과 유사했다는 연구결과-(Sharon \& Woolley, 2004)와 맥을 같이한 다. 즉 유아기 내에서도 연령에 따라 가상의 존재가 물리적으 로 존재하는 실체인지에 대한 이해가 달라짐을 확인하였다.

다섯째, 유아는 의인화와 사실성이 모두 낮은 캐릭터의 실 재성을 다른 세 종류의 의인화된 캐릭터보다 더 높게 추론하 였다. 이는 의인화 수준이 낮은 혼합형 캐릭터가 사실성 수준 이 낮은 $2 \mathrm{D}$ 애니메이션으로 제시되는 경우 의인화된 캐릭터 의 실재성이 높게 인식된 것이다. 즉, 만화의 형태로 제시된 혼 합형 캐릭터가 실제로 볼 수 있고, 소리를 들을 수 있고, 만질 수 있는 존재로 여겨졌음을 의미한다. 의인화 수준이 낮을 때 실재성이 높게 인식된 것은 앞서 언급했듯이 의인화된 캐릭 터가 유아에게 동물의 재현으로 인식된 것과 같은 맥락으로 보인다. 즉 의인화 수준이 낮은 캐릭터는 동물로 여겨졌기 때 문에 실제로 볼 수 있고, 만질 수 있는 존재로 인식되었다. 한 편, 사실성이 낮은 $2 \mathrm{D}$ 애니메이션이 사실성이 높은 실사영화 보다 실재성이 높게 인식된 것은 $3 \mathrm{D}$ 기술이 리얼리즘의 문제 를 야기할 정도로 사실보다 더 사실 같은 영상을 구현한 것 $(\mathrm{G}$. Jeon, 2010)을 고려할 때 의외의 결과라고 할 수 있다. 사람들 은 사실적인 애니메이션을 선호하면서도 지나치게 사실적인 애니메이션을 거부하는 경향이 있으며, 이러한 심리상태를 언 캐니 밸리(uncanny valley)라고 칭하는데, 본 연구결과도 언캐 니 밸리를 통해 해석할 수 있을 것이다. 언캐니 밸리는 본래 로 봇공학 분야에서 사용된 용어로, 로봇과 인간의 유사성이 증 가할 때 로봇에게 느끼는 호감도가 증가하다가 어느 수준에 이르면 감소하는 지점이 있으며, 그 감소 지점을 의미하는 용
어이다(Mori, 1970). 섬뜩함, 불쾌함, 혐오스러움을 의미하는 언캐니는 $3 \mathrm{D}$ 애니메이션에서 사실적으로 표현된 캐릭터에게 관객이 느끼는 감정에도 적용가능한데, 캐릭터를 사실적으로 표현한 그래픽이 관객에게 이질감을 주기 때문에 언캐니 밸리 가 나타날 수 있다(S.-D. Park \& Jung, 2014). 유아가 사실성이 높은 의인화된 캐릭터에게 언캐니 밸리를 보이는지에 관한 연 구는 매우 제한적인 실정이다. 아동을 대상으로 인간과 가상 캐릭터에 대한 언캐니 밸리를 조사한 연구에서, 12 개월 영아 가 인간과 가상 캐릭터를 구분하여 인간 얼굴 보기를 선호하 였고(Lewkowicz \& Ghazanfar, 2012), 9세에서 11세 아동은 가 상 캐릭터의 얼굴 표정과 정서에 따라 친숙하거나 낮설게 느 끼는 정도가 달랐다는 결과(Tinwell \& Sloan, 2014)를 고려할 때, 컴퓨터 그래픽을 통해 사실적으로 제시된 의인화된 캐릭 터는 유아에게 이질적으로 느껴져 실재성이 낮게 인식된 것으 로 보인다.

이상의 결론은 다음과 같은 제한점을 고려하여 해석할 필 요가 있다. 먼저 이 연구는 애니메이션과 실사영화의 맥락에 서 제시된 의인화된 캐릭터에 대한 유아의 생명현상 인지를 살펴 본 것으로, 제한된 시간동안 상영되는 영상이 대상의 특 징을 충분히 드러내지 못했을 가능성이 있다. 다음으로 이 연 구는 의인화된 동물 캐릭터에 대한 유아의 생명현상 인지 및 추론을 살펴본 것으로, 스펀지 밥이나 로보카 폴리 같이 사물 이 의인화된 캐릭터에 대한 유아의 생명현상 이해는 포함하지 못했다는 한계가 있다. 후속 연구에서는 의인화된 동물 캐릭 터 뿐 아니라 의인화된 사물 캐릭터 혹은 의인화된 자연물 캐 릭터를 포함하여 유아의 생명개념을 보다 포괄적으로 파악할 필요가 있으며, 이러한 의인화된 캐릭터가 유아에게 어떤 존 재로 인식되는지를 알아보는 연구를 제안한다.

이러한 제한점에도 불구하고 이 연구는 다음과 같은 이론 및 실천적 의의를 지닌다. 첫째, 이 연구는 유아의 생명현상 인 지와 관련하여 경계선적 대상인 의인화된 캐릭터를 대상으로 생명현상 인지 및 추론을 밝혔다. 의인화된 캐릭터는 물리적 으로는 실재하지 않지만 심리적으로 실재한다고 여겨지는 존 재로, 유아의 생명현상 인지를 알아본 지금까지의 연구들에서 부족했던 가상의 존재에 대한 생명현상 인지 및 추론 결과를 밝혔다는 점에서 의의가 있다. 둘째, 생명현상 인지와 관련하 여 5세 유아는 3세 유아에 비해 의인화된 캐릭터의 실재성을 낮게 인지하고 있었다. 이러한 결과는 5 세 유아의 생명현상 이 해 수준을 전조작기 물활론으로 이해하기 불충분하며, 유아기 내에서도 연령에 따른 수준의 차이가 있는 것으로 해석되었 다. 셋째, 유아가 경계선적 대상인 의인화된 캐릭터의 특성을 
추론할 때 단일한 기준을 가지고 있지 않음을 확인하였다. 즉, 유아에게 대상이 살아있는지, 생물특성이 있는지, 심리특성이 있는지, 실재성이 있는지 묻는 질문에 따라 유아의 응답이 달 라졌다. 3 세 유아에게 의인화된 캐릭터는 살아있으며, 생물특 성과 심리특성을 갖는 물리적 실체로 인지된 것에 반해, 5세 유아에게 의인화된 캐릭터는 생물특성과 심리특성을 가지면 서 실재하지 않는 존재로 인식되고 있음을 확인하였다. 넷째, 의인화된 캐릭터의 의인화 수준이 낮은 것이 유아가 대상을 생물특성을 지닌 존재이자 실재하는 존재로 여기는 데 영향을 미치고, 사실성 수준이 낮은 것이 유아가 대상을 실재하는 존 재로 여기는 데 영향을 미침을 확인하였다. 캐릭터의 속성인 의인화와 사실성 수준이 캐릭터가 실재하고 살아있다고 인식 하는데 영향을 미침을 실증적으로 확인함으로써 의인화된 캐 릭터를 사용한 애플리케이션 등 유아를 대상으로 한 교육매체 를 구성 할 때 참고할 수 있는 기초적인 자료를 마련하였다. 즉 동물 캐릭터에 인간적 요소를 많이 부여하거나 컴퓨터 그래픽 을 활용하여 캐릭터를 사실적이고 실감나게 묘사하는 것보다 애니메이션 맥락에서 동물의 특성을 많이 가지고 있는 캐릭터 를 제시하는 것이 유아와 더 효과적으로 의사소통을 하는 방 법이 될 수 있다.

\section{Acknowledgements}

This study was supported by the BK21 Plus Program of National Research Foundation of Korea Grant funded by the Korean Government (NRF-22B20152813529)

\section{Notes}

This article is a part of the first author's master's thesis submitted in 2014, and was presented as a poster at the 2014 Annual Spring Conference of the Korean Association of Child Studies.

\section{Conflict of Interest}

No potential conflict of interest relevant to this article was reported.

\section{References}

\section{In English}

Anthropomorphism. (n.d.) In Britannica Encyclopedia online. Retrieved from https://www.britannica.com/topic/ anthropomorphism

Animism. (n.d.) In Cambridge Dictionary online. Retrieved from https://dictionary.cambridge.org/ko/\%EC\% $82 \% \mathrm{AC} \% \mathrm{EC}$ \%A0\%84/\%EC\%98\%81\%EC\%96\%B4/animism

Carey S. (1985). Conceptual change in childhood. Cambridge, MA: MIT Press.

Clark, C. D. (1995). Fights of fancy, leaps of faith: Children's myths in comtemporary America. Chicago, IL: University of Chicago Press.

Corriveau, K. H., Kim, A. L., Schwalen, C. E. \& Harris, P. L. (2009). Abraham Lincoln and Harry Potter: Children's differentiation between historical and fantasy characters. Cognition, 113(2), 213-225. doi:10.1016/j.cognition.2009.08.007

Flavell, J. H., Flavell, E. R., Green, F. L., \& Korfmacher, J. E. (1990). Do young children think of television images as pictures of real objects?. Journal of Broadcasting \& Electronic Media, 34(4), 399-419. doi:10.1080/08838159009386752

Gelman, S. A. \& Gottfried, G. M. (1996). Children's causal explanations of animate and inanimate motion. Child Development, 67(5), 1970-1987. doi:10.1111/j.1467-8624.1996.tb01838.x

Guthrie, S. E. (1993). Faces in the clouds: A new theory of religion. New York: Oxford University Press.

Hatano, G. \& Inagaki, K. (1994). Young children's naive theory of biology. Cognition, 50(1-3), 171-188. doi:10.1016/00100277(94)90027-2

Inagaki, K. \& Hatano, G. (1996). Young children's recognition of commonalities between animals and plants. Child Development, 67(6), 2823-2840. doi:10.1111/j.1467-8624.1996.tb01890.x

Jibson, J. L. \& Gelman, S. A. (2007). Robot and rodents: Children's inferences about living and nonliving kinds. Child Development, 78(6), 1675-1688. doi:10.1111/j.14678624.2007.01095.x

Jones, S. S., Smith, L. B., \& Landau, B. (1991). Object properties and knowledge in early lexical learning. Child Development, 62(3), 499-516. doi:10.1111/j.1467-8624.1991.tb01547.x

Lewkowicz, D. J., \& Ghazanfar, A. A. (2012). The development of the uncanny valley in infants. Developmental Psychobiology, 54(2), 124-132. doi:10.1002/dev.20583

Margett, T. E. \& Witherington, D. C. (2011). The nature of preschoolers' concept of living and artificial objects. Child Development, 82(6), 2067-2082. doi:10.1111/j.14678624.2011.01661.x

Mori, M. (1970). The uncanny valley. Energy, 7(4), 33-35. 
Massey, C. M. \& Gelman, R. (1998). Preschooler's ability to decide whether a photographed unfamiliar object can move itself. Developmental Psychology, 24(3), 307-317. doi:10.1037/0012-1649.24.3.307

Okita, S. Y. \& Schwartz, D. L. (2006). Young children's understanding of animacy and entertainment robots. International Journal of Humanoid Robotics, 3(3), 393-412. doi:10.1142/ S0219843606000795

Okita, S. Y., Schwartz, D. L., Shibata, T., \& Tokuda, H. (2005). Exploring young children's attributions through entertainment robots. In Robot and Human Interactive Communication, 2005. ROMAN 2005. IEEE International Workshop on (pp. 390-395). IEEE. doi:10.1109/ ROMAN.2005.1513810

Opfer, J. E. \& Gelman, S. A. (2011). Development of the animateinanimate distinction. In U. Goswami (Ed.), The WileyBlackwell handbook of childhood cognitive development (2nd ed., pp. 213-238). Chichester, West Sussex: WileyBlackwell.

Piaget, J. (1929). The child's conception of the world. London: Routledge \& Kegan Paul.

Power, P. (2008). Character animation and the embodied mind-brain. Animation, 3(1), 25-48. doi:10.1177/1746847708088734

Rakison, D. H. \& Butterworth, G. E. (1998). Infants' use of object parts in early categorization. Developmental Psychology, 34(1), 49-62. doi:10.1037/0012-1649.34.1.49

Sharon, T., \& Woolley, J. D. (2004). Do monsters dream? Young children's understanding of the fantasy/reality distinction. British Journal of Developmental Psychology, 22(2), 293-310. doi:10.1348/026151004323044627

Skolnick, D. \& Bloom, P. (2006). What does Batman think about SpongeBob? Children's understanding of the fantasy/ fantasy distinction. Cognition, 101(1), B9-B18. doi:10.1016/ j.cognition.2005.10.001

Tinwell, A., \& Sloan, R. J. S. (2014). Children's perception of uncanny human-like virtual characters. Computers in Human Behavior, 36, 286-296. doi:10.1016/j.chb.2014.03.073

Turkle, S. (2005). The second self: Computers and the human spirit. London: Mit Press.

Woolley, J. D. \& Wellman, H. M. (1990). Young children's understanding of realities, nonrealities, and appearances. Child Development, 61(4), 946-961. doi:10.1111/j.14678624.1990.tb02833.x

\section{In Korean}

Cho, H.-J., \& Yi, S.-H. (2002). Children's cognition of televised physically impossible events: Effects of characteristics of the task. Korean Journal of Child Studies, 23(3), 123-137.
Hong, N. (2008). Study of the difference between 2D animation and actual film in hyperrealistic narrative. The Korean Journal of Animation, 4(1), 169-190.

Hyun, E., \& Son, S. (2011). Is robot alive?: Young children's perception of a teacher assistant robot in a classroom. Korean Journal of Child Studies, 32(4), 1-14.

Jeon, D., \& Moon, J. (2012). The robot in the view point of the definition of life. Studies on Life and Culture, 23, 172-191.

Jeon, G. (2010). Visual textuality of stereoscopic 3D animation. Catoon \& Animation Studies, (20), 31-45

Kim, M.-J., \& Kwak, N.-J. (2017). A study on convergence of 2D and $3 \mathrm{D}$ animation: Focused on character and expression technique. Catoon \& Animation Studies, (48), 45-67. doi:10.7230/KOSCAS.2017.48.045

Kim, M. K. (2017). 3, 4, and 5-year-old children's judgement and reasoning of the life phenomenon on humanoid intelligent robot (Doctoral dissertation). Retrieved from http://www. riss.kr/link?id=T14618736

Kim, M.-J. (2008). A study of the differentiation of the conception of 'life' by a cross-sectional analysis (Unpublished master's thesis). Korea National University of Education, Chungbuk, Korea.

Kim, S. N. (2003). An analysis of the selection of recommended book listings and the characteristics of the books for young children in South Korea (Unpublished master's thesis). Sungkyunkwan University, Seoul, Korea.

Kum, B.-S. (2004). Comparative study on Mise-en-Scène on animation and live-action movies: Focusing on <Ghost in the shell> and <Blade Runner> (Unpublished master's thesis). Sejong University, Seoul, Korea.

Lee, Y.-S., Hong, S.-H., \& Kim, J.-H. (2010). Expression of anthropomorphized animal characters in animations. Journal of the Korea Contents Association, 10(11), 125-135. doi:10.5392/JKCA.2010.10.11.125

Lee, Y.-S., \& Kim, J.-H. (2009). A study on the step of anthropomorphizing animal characters in animations. Journal of Korea Multimedia Society, 12(11), 1661-1670.

Lee, Y.-S., Kim, W.-H., \& Kim, S.-N. (2015). A study on the difference of affect intensity according to the degree of anthropomorphism in animated animal characters. Journal of Korea Society of Design Forum, 46, 375-388.

No, B. R., \& Yi, S. H. (2017). Children's cognition and inference of the life phenomenon about robotic dogs. The Journal of Korea Robotics Society, 12(3), 365-375. doi:10.7746/ jkros.2017.12.3.365

Park, C. (2014). A study on the visual amusement of animation in real film. Journal of Communication Design, 49, 108-115

Park, S.-D., \& Jung, Y.-J. (2014). Analysis and proposal of abstractive expression of 3D animation. Catoon \& Animation Studies, 1-24. doi:10.7230/KOSCAS.2014.37.001

Park, S.-W. (2003). A study on the motive of anthropomorphic 
expression in character design. Journal of Basic Design \& Art, 4(2), 13-21.

Park, Y., \& Yi, S. (2007). Preschoolers' use of trait labels to make inferences about people according to their age and task variables. The Korean Journal of Developmental Psychology, 20(2), 77-94.

Rieh, J.-G. (2005). Metamorphosis of reality in animation. Catoon \& Animation Studies, 220-234.

Sung, Y., Lee, I. \& Jung, Y. (2004). Consumer's response to the character: Is Mickey a mouse? The Korean Journal of Advertising, 15(3), 39-69.

\section{ORCID}

Boram No http://orcid.org/0000-0001-6456-2174

Soonhyung Yi http://orcid.org/0000-0002-3381-1788

Received November 5, 2017

Revision received December 28, 2017

Accepted February 15, 2018 